\title{
ORIENTAÇ̃̃O PRÉ-OPERATÓRIA: ANÁLISE COMPREENSIVA SOB A ÓTICA DO CLIENTE
}

PREOPERATORY ORIENTATION: COMPREHENSIVE ANALYSIS UNDER CLIENT'S VIEW.

\author{
Eucléa Gomes Vale ${ }^{1}$ \\ Maria Fernandes Amorim ${ }^{2}$ \\ Cristiana Bitu Freitas ${ }^{3}$ \\ Fernanda Pereira Melo ${ }^{4}$
}

\begin{abstract}
RESUMO: Abordamos o tema Orientação Pré-Operatória como uma prática imprescindivel da intervenção de enfermagem, para identificar facetas da percepção do cliente acerca das informações recebidas antes da cirurgia. Reconhecemos as falhas desta ação no cotidiano das Unidades Cirúrgicas delimitadas em um Hospital Geral de Fortaleza-CE, a falta de um guia do preparo de pacientes para o ato cirúrgico. Portanto, investigamos a temática citada para dimensionar o problema, descrevê-lo e analisarmos o prosseguimento de uma trajetória iniciada nos contatos iniciais com a abordagem fenomenológica. Utilizando os pressupostos desta alternativa metodológica, pudemos compreender o paciente em fase pré-operatória, segundo o referencial de Martins \& Bicudo. Assim analisamos o conhecimento captado através das falas dos pacientes: seu significado e a repercussão no atendimento individual, enquanto ação que satisfaz as suas, necessidades no cotidiano do trabalho de enfermagem. Nessa experiência de estar orientando pacientes para enfrentarem a intervenção cirúrgica, abrimos, então um espaço que nos possibilitou conduzí-los ao reconhecimento de sua dimensão existencial do vivenciar uma intervenção cirúrgica.
\end{abstract}

UNITERMOS: Orientação pré-operatória - Enfermagem - Vivência de intervenção cirúrgica.

\footnotetext{
${ }^{1}$ Enfermeira, Mestre em Educação, Diretora da Divisão Técnica do Hospital Geral de Fortaleza. Professora do Curso de Enfermagem da Universidade Estadual do Ceará - CE.

${ }^{2}$ Enfermeira Especializanda no Curso de Administração de Serviços de Saúde Pública. Enfermeira do Centro Cirúrgico do Hospital Geral de Fortaleza. - CE.

${ }^{3}$ Enfermeira, Especializanda em Enfermagem Médico-Cirúrgica. Enfermeira da Unidade Coronariana do Hospital de Messejana - CE.

${ }^{4}$ Enfermeira, Chefe do Centro Cirúrgico Eletivo do Hospital Geral de Fortaleza. Especialista em Enfermagem em Centro Cirúrgico e Enfermagem Médico-Cirúrgica.
} 


\begin{abstract}
In this study we approach the issue preoperatory orientation which we understand to be a vital practice in the field of Nursing also allowing the identification of same features at clients perception regarding the information achieved before operation. It is also suitable to recognize the failure of this procedure in the daily work at surgical units which upsets us with the absence of a guideline for preparing patients to surgical acts. Facing this need, we have decided to deeply investigate this issue to achieve the dimension, the description and analyzing the trajectory follow-up started in the first coniact with the phenomenological approach. Thus, we make use of our patient operatory phase through his talk according to MARTINS \& BICUDO's reference. So, this research aims at presenting the knowledge feature achieved through patients talk, its meaning and repercussion onto the individual plane as well as identifying what should alone improve it. That is the way phenomenological method questions the need of a preoperatory orientation which links us to theme dimension. In our experience of guiding patients to cope with their surgical intervention, we open a space that allows us to intervene under the perspective of conducting patients to recognize their existential dimension of experiencing an operation.
\end{abstract}

KEYWORDS: Guidelines - Nursing intervention - Operation - Orientation.

\title{
CONSIDERAÇÕES INICIAIS
}

Nesse estudo procuramos entender a orientação pré-operatória, de enfermagem, como uma ação que permite identificar a percepção do cliente acerca das informações recebidas antes da cirurgia. Por oportuno, vale salientar que muito nos incomoda a falta de preparo dos pacientes para o ato cirúrgico e é em face desta necessidade que decidimos investigar o fenômeno ORIENTAÇÃO PRÉ-OPERATÓRIA RECEBIDA POR PACIENTES SUBMETIDOS A INTERVENÇÃO CIRÚRGICA, de forma intencional, envolvidos em uma interrogação que nasceu dentro do nosso mundo vida.

Interagem assim, nesse mundo vida, imaginação e experiência, fenômeno este que será desvendado a posteriori, caminhando no mundo de nossas experiencias, realizando transformações e criando novos horizontes de possibilidades. Nossa experiência nessa perspectiva se constitui pelo conjunto de horizontes que vamos incorporando ao longo de nossa vivência. Esses horizonte incluem as transformações que existem em nós pelo conhecimento experienciado. 


\section{TRAJETÓRIA DOS PESQUISADORES RUMO À COMPREENSÃO DO FENÔMENO}

A razão da nossa preocupação, em relação ao fenômeno em estudo, levounos a buscar meios de entender e compreender o significado da orientação préoperatória efetuada junto a pacientes cirúrgicos. Destarte, o nosso olhar, ao interrogar o mundo-vida desses sujeitos, conduziu-nos para uma pesquisa de cunho qualitativo com respaldo nos fundamentos fenomenológicos de Martins \& Bicudo (1994).

As percepções do sujeito são enfatizadas na experiência viva, no mundo como ele é vivido. A pesquisa qualitativa procura imprimir um rigor diferente do conseguido com a previsão numérica aos fenômenos não passíveis de quantificação, tais como angústia, ansiedade, medo, alegria, tristeza, cólera, amor e solidão (Martins \& Bicudo, 1994).

Boemer (1994) acrescenta que, na pesquisa fenomenológica, o pesquisador não vai partir de um problema, mas de uma interrogação, buscando percorrê-la até sua compreensão.

Com esta abordagem compreensiva, pautada na experiência concreta vivida no cotidiano, buscamos interrogar o significado dessa vivência pré-operatória recebida pelos pacientes que se submeteram a intervenção cirúrgica, e o modo como esta é interpretada pelo ser que a experiencia. Nessa perspectiva, o ser, ao experienciar o mundo enquanto unidade, vislumbra horizontes que vão além do momento presente da experiência.

Esse ato de vislumbrar horizontes, que vão além do mundo experienciado, se constitui na imaginação e, quando se concentra em sua essência, caracteriza-se como experiência vivida sob a forma de sentimento.

\section{O ACESSO AO MUNDO-VIDA DOS PACIENTES CIRÚRGICOS}

Considerando nossas interrogações quanto ao fenômeno que estamos querendo desvendar nesta investigação; tornam-se importantes os discursos e as experiências dos pacientes que vivenciam a orientação pré-operatória, tendo em vista que a compreensão se estabeleceu entre o sujeito que vivenciou o fenômeno e os pesquisadores que os interrogaram.

Para obtenção dessas descrições, buscamos uma instituição pública de Fortaleza - CE. - Clínica Cirúrgica - onde os pacientes adultos são assistidos / cuidados por uma equipe de enfermagem, que se reveza nos três turnos e procura manter um atendimento que atenda às necessidades dos pacientes I clientes.

As entrevistas foram realizadas com pessoas que tinham sido operadas e submetidas à orientação pré-operatória efetuada por enfermeiras do Centro Cirúrgico. Estas foram norteadas ela seguinte solicitação: Fale-me sobre sua orientação pré-operatória. A partir daí foi surgindo a necessidade de esclarecer a 
qualidade dessa orientação e, assim, questionamos: as orientações esclareceram suas dúvidas?

Nesse momento, deixamos os pacientes falarem a vontade e em algumas situações solicitávamos aos mesmos que esclarecessem pontos de sua fala, utilizando as últimas palavras ditas pelo sujeito da experiência, participantes da investigação, e também frases como estas: Como foi isso? Explique mais um pouco essa experiência.

A transcrição das descrições foram feitas por nós, em duas etapas: na primeira, feita integralmente e, na segunda, subtraimos as frases ou palavras que davam continuidade ao discurso, deixando desta forma a descrição contínua.

O período de coleta das descrições foi mantido até o momento que se iniciou a repetição e as descrições foram encaminhadas para a visualização de convergências, mostrando que estava se delineando o fenômeno investigado. Este período abrangeu um mês, totalizando as descrições de cinco pacientes.

\section{REFLETINDO SOBRE ESTE ESTUDO}

Realizamos esta pesquisa com o propósito de tentar ter acesso ao mundo vida dos pacientes que receberam orientação pré - operatória realizada por enfermeiros do Centro Cirúrgico, descrevendo e compreendendo os sentimentos em relação às orientações recebidas e a importância dessas, na segurança dos mesmos.

A análise por nós empreendida foi apenas um momento de reflexão, pois ela tem imbuída em si o caráter do não esgotamento porque o fenômeno se revela sob alguns aspectos, enquanto se oculta sob outros.

Identificamos em nosso desvelamento cinco unidades de significados que nos permitiram compreender a experiência vivida pelos pacientes cirúrgicos que receberam orientação pré-operatória individualizada e sistematizada.

Apresentamos e analisamos o corpo de conhecimento captado através das falas dos pacientes: seu significado e a repercussão no atendimento individual, enquanto ação que satisfaz as necessidades sentidas por eles. Neste sentido, o método fenomenológico interroga esse fenômeno nas situações que se apresentam em nosso cotidiano. Esse reconhecimento traduzido nos remete à questão da necessidade de orientação pré-operatória, que nos compromissa com a dimensão do tema. Nessa experiência de estar orientando pacientes para enfrentar a intervenção cirúrgica, empenhamo-nos na abertura de um espaço que nos possibilitasse intervir, sob a perspectiva de conduzir os pacientes para reconhecerem a sua dimensão existencial do vivenciar essa experiência. 
"O preparo foi ótimo, vocês realmente dizem tudo, não tive nenhuma dúvida, nada foi surpresa para mim."

Ao observar estas falas fica bem claro o quão importante foi para estes pacientes a presença de um profissional enfermeiro durante o momento préoperatório não só em relação as orientações recebidas mas também como apoio psicológico evidenciando-se através da segurança com que estes expressaram seus sentimentos em relação ao procedimento cirúrgico.

"Já me operei outra vez e não tive tanta explicação. Foi ótima saber detalhes e ver a dedicação das enfermeiras"

Neste relato o cliente teve a oportunidade de falar sobre duas experiencias, de certa forma idênticas, mas que possibilitaram sentimentos tão distintos. Para Martins \& Bicudo (1994) as experiências não se repetem porque cada momento é único e pleno de possibilidades. Acredita-se que os detalhes discutidos durante o preparo pré-operatório foram fundamentais para que sentimentos fossem expressados de forma a oferecer mais segurança. Percebe-se também que durante o contato pré-operatório houve um entrosamento entre cliente/profissional que repercutiu em uma avaliação qualitativa positiva quando este exaltou a dedicação do profissional enfermeiro.

"Vocês são ótimas, explicam tudo direitinho. Tiram todas as nossa dúvidas.

O único medo é da anestesia."

Nestas falas, os pacientes exaltam a importância do preparo pré-operatório efetuado pelas enfermeiras do Centro Cirúrgico trazendo-Ihes, orientações acerca do procedimento cirúrgico e transmitindo-Ihes segurança. Nota-se, no entanto, que a anestesia continua sendo um procedimento que Ihes dá medo e acredita-se que este sentimento esteja ligado à perda transitória da consciência em decorrência do ato anestésico.

"O meu medo foi da anestesia. O resto foi tranqüilo. Foi bom encontrar alguém que eu já conhecia".

Nesta fala também percebe-se o receio em relação ao ato anestésico. Notase que este cliente sentiu-se seguro diante do procedimento cirúrgico e acreditase que a orientação pré-operatória foi fundamental para que este sentimento se evidenciasse. A visita traz também a possibilidade de um contato prévio com um profissional que o acompanharia durante a fase trans-operatória, o que foi significativo para sua segurança neste momento estressante de sua hospitalização.

O mostrar-se desse fenômeno pode trazer alternativas para um repensar da assistência pré-operatória realizada de forma sistemática, individualizada e que atenda às necessidades do cliente. 


\section{BIBLIOGRAFIA CONSULTADA}

1. BOEMER, M. R. A Condução de Estudos Segundo a Metodologia de Investigação Fenomenológica. $R$. Latino-Americana de Enferm. Ribeirão Preto, v. 2, n. 1, p. 83-84,1994.

2. MARTINS, J., BICUDO, M. A. V., A Pesquisa Quantitativa em Psicologia: Fundamentos e Recursos Básicos, 2. ed. São Paulo: Morais, 1994. 110 p.

3. MAY, R. O que é ansiedade, In: O homem a Procura de Si Mesmo. 20. ed. Petrópolis: Vozes, 1994. Cap. 3, p. 33-38.

4. STEFANELLI, M. C. Importância do Processo de Comunicação na Assistência de Enfermagem R. Esc. Enferm. USP. São Paulo. v. 15, n. 3, p. 239-245, 1981. 